\title{
BMJ Open Risk of aortic dissection, congestive heart failure, pneumonia and acute respiratory distress syndrome in patients with clinical vertebral fracture: a nationwide population-based cohort study in Taiwan
}

\author{
Feng-You Lee, ${ }^{1,2}$ Wei-Kung Chen, ${ }^{3}$ Cheng-Li Lin, ${ }^{4,5}$ Chia-Hung Kao (D) , ,,7 \\ Tse-Yen Yang (1) , ${ }^{8,9}$ Ching-Yuan Lai ${ }^{3}$
}

To cite: Lee F-Y, Chen W-K, Lin C-L, et al. Risk of aortic dissection, congestive heart failure, pneumonia and acute respiratory distress syndrome in patients with clinical vertebral fracture: a nationwide population-based cohort study in Taiwan. BMJ Open 2019;9:e030939. doi:10.1136/ bmjopen-2019-030939

- Prepublication history and additional material for this paper are available online. To view please visit the journal (http:// dx.doi.org/10.1136/bmjopen2019-030939).

$\mathrm{T}-\mathrm{YY}$ and $\mathrm{C}-\mathrm{YL}$ contributed equally.

Received 08 April 2019 Revised 14 October 2019 Accepted 21 October 2019

Check for updates

(C) Author(s) (or their employer(s)) 2019. Re-use permitted under CC BY-NC. No commercial re-use. See rights and permissions. Published by BMJ.

For numbered affiliations see end of article.

Correspondence to Dr Tse-Yen Yang; yang_t_y@yahoo.com.tw

\section{ABSTRACT}

Objective Studies on the association between clinical vertebral fractures (CVFs) and the subsequent risk of cardiopulmonary diseases, including aortic dissection (AD), congestive heart failure (CHF), pneumonia and acute respiratory distress syndrome (ARDS) are scarce. Therefore, we used the National Health Insurance Research Database to investigate whether patients with CVF have a heightened risk of subsequent $A D, C H F$, pneumonia and ARDS.

Design The National Health Insurance Research Database was used to investigate whether patients with CVFs have an increased risk of subsequent $A D, C H F$, pneumonia and ARDS. Participants This cohort study comprised patients aged $\geq 18$ years with a diagnosis of CVF and were hospitalised at any point during 2000-2010 ( $n=108935)$. Each CVF patient was frequency-matched to a no-CVF hospitalised patients based on age, sex, index year and comorbidities $(n=108935)$. The Cox proportional hazard regressions model was used to estimate the adjusted effect of CVF on $A D, C H F$, pneumonia and ARDS risk.

Results The overall incidence of $A D, C H F$, pneumonia and ARDS was higher in the CVF group than in the no-CVF group (4.85 vs $3.99,119.1$ vs $89.6,283.3$ vs 183.5 and 9.18 vs 4.18/10 000 person-years, respectively). After adjustment for age, sex, comorbidities and Charlson comorbidity index score, patients with CVF had a 1.23-fold higher risk of $\mathrm{AD}(95 \% \mathrm{Cl}=1.03-1.45), 1.35$-fold higher risk of $\mathrm{CHF}$ $(95 \% \mathrm{Cl}=1.30-1.40), 1.57$-fold higher risk of pneumonia $(95 \% \mathrm{Cl}=1.54-1.61)$ and 2.21 -fold higher risk of ARDS $(95 \% \mathrm{Cl}=1.91-2.57)$ than did those without CVF. Patients with cervical CVF and SCl were more likely to develop pneumonia and ARDS.

Conclusions Our study demonstrates that CVFs are associated with an increased risk of subsequent cardiopulmonary diseases. Future investigations are encouraged to delineate the mechanisms underlying this association.

\section{INTRODUCTION}

Clinical Vertebral fractures (CVFs) constitute a major healthcare burden worldwide
Strengths and limitations of this study

- This is the first population-based, longitudinal cohort study to focus on the correlation between CVF and the subsequent risks of specific cardiopulmonary diseases.

- By sampling from a large nationwide database, which covers nearly $100 \%$ of all residents in Taiwan, stable outcomes could be achieved with such adequate, representative samples.

- All disease definitions and sample selection in our study were based on the ICD-9-CM coding. Therefore, miscoding or misclassification might exist, although it is considered rare.

- In our study, sampled participants were retrieved from NHIRD from January 1, 2000, to December 31, 2010 . Aging property of the data might not truly reflect the current medical conditions.

- Because of geographic and epidemiologic discrepancies, our results might not be applicable to other countries or regions.

because of its high incidence and strong influence on individuals' quality of life, medical resource consumption and direct or potential unfavourable impacts on socioeconomic development. ${ }^{1-3}$ Approximately 1.4 million new cases of CVF are diagnosed globally every year, ${ }^{4}$ and among these, osteoporosis, trauma and malignancy are the major etiologies. ${ }^{5-9}$ Acute aortic dissection $\mathrm{AD})$ remains the major life-threatening vascular emergency, with a steadily increasing incidence because of population ageing and the explosive growth of radiologic technology. ${ }^{10-12}$ Without early recognition and timely treatment, the prognosis of $\mathrm{AD}$ would be extremely poor, and half the patients 


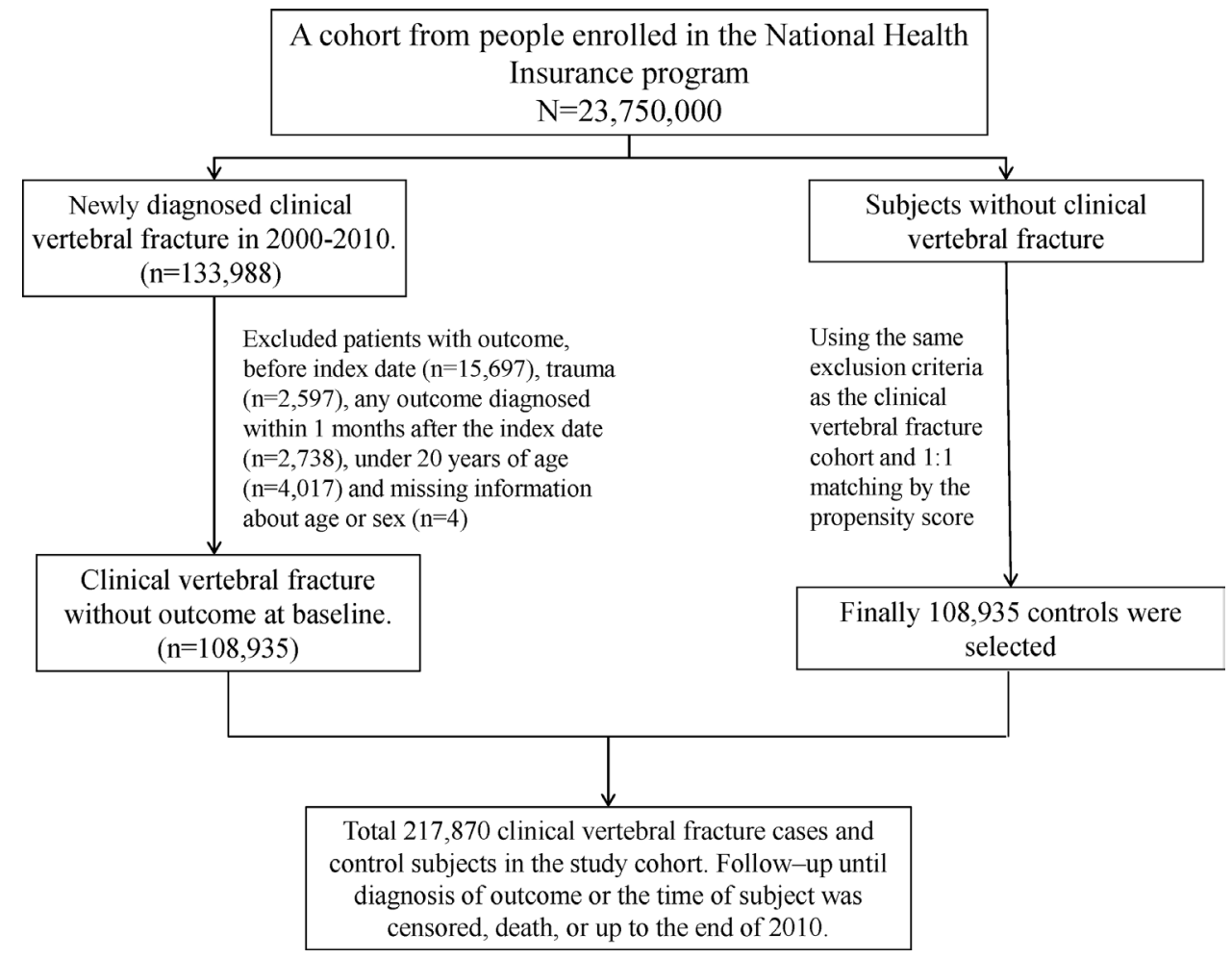

Figure 1 Derivation of our study cohort.

would die within $48 \mathrm{~h}^{10}$. Congestive heart failure (CHF) is the major cause of hospitalisation in old age, with more than 650000 new cases confirmed annually in the United States, and more than 1 million people were hospitalised for decompensated CHF, resulting in costs exceeding 39 billion $^{13-15}$. Pneumonia is one of the most common infectious diseases in elderly adults and is also the leading cause of death in Americans older than 65 years ${ }^{16}{ }^{17}$ Acute respiratory distress syndrome (ARDS) is a complex syndrome characterised by diffuse hydrostatic pulmonary oedema, alveoli damage and persistent hypoxemia, which are mainly triggered by infection, inflammation, trauma, or other etiologies. The in-hospital mortality rate for this condition could reach $40 \%$ even when managed with the standardised lung protective ventilator strategy. ${ }^{18} 19$

Studies have demonstrated that elderly patients with a history of osteoporotic vertebral fracture have an increased risk of cardiovascular events, including stroke (ischaemic or haemorrhagic) and coronary heart disease. ${ }^{20-23}$ Recently, Kim et $a l^{24}$ reported an association between isolated CVF and future development of pneumonia in women with low bone density. In addition, chronic, worsened and longstanding backache accompanied with CVF might result in a long-term increase of sympathetic tone, fatigue, stress reaction, low physical activity, depressive tendency, diminished pulmonary function and, consequently a poor quality of life, which might be correlated with cardiopulmonary disease risk. ${ }^{357825}$ Therefore, we hypothesised that an association exists between CVF and the risk of cardiopulmonary diseases, including AD, CHF, pneumonia and ARDS. Accordingly, we conducted a nationwide, population-based data analysis to verify this hypothesis and tried to provide essential evidence-based information for clinical practice.

\section{METHODS}

\section{Data source}

This retrospective cohort study used datasets from Taiwan's National Health Insurance Research Database (NHIRD). Taiwan launched a single-payer National Health Insurance (NHI) programme in March 1995, and 99\% of the 23.74 million residents were enrolled. ${ }^{26}$ The details of the NHIRD and NHI programme are well presented in previous studies. ${ }^{27-33}$ The NHIRD records diseases according to International Classification of Diseases, Ninth Revision, Clinical Modification (ICD-9-CM) codes. Validation of the NHIRD with cardiovascular diseases were investigated and appeared to be a valid resource for population research. ${ }^{34-37}$ This study was approved by the Institutional Review Board of China Medical University Hospital (CMUH-104-REC2-115-CR4).

\section{Sampled participants}

Patients aged $\geq 18$ years with newly diagnosed CVF (ICD-9-CM codes, 805 and 806) from January 1, 2000, to December 31, 2010, were identified as the CVF cohort. Study subjects with the diagnosis of vertebral fracture from 1996 to 1999 were excluded at the baseline. The location of CVF was defined in two ways as follows: (1) cervical spine (ICD-9-CM codes, 805.0-805.18 and 806.0-806.19), thoracic spine (ICD-9-CM codes, 805.2, 805.3 and 806.2806.39), lumbar spine (ICD-9-CM codes, 805.4, 805.5, 806.4 and 806.5 ) and sacrum plus coccyx (ICD-9-CM codes, 
805.6, 805.7 and 806.6-806.79) and (2) without spinal cord injury (SCI) (ICD-9-CM codes, 805-805.9) and with SCI (ICD-9-CM codes, 806-806.9). The date of first-time CVF diagnosis at admission was defined as the index date. Participants with prior AD (ICD-9-CM codes, 441.0, 441.00, 441.01, 441.02 and 441.03), CHF (ICD-9-CM code, 428), pneumonia (ICD-9-CM codes, 480-488) and ARDS (ICD-9-CM codes, 518.82 and 518.5) before 1999 and before the index date $(\mathrm{n}=15697)$; with the diagnosis of trauma (ICD-9-CM codes, 800-959 except 805-806) during the same period $(\mathrm{n}=2597)$; with any outcome event $(\mathrm{AD}, \mathrm{CHF}$, pneumonia and ARDS) diagnosed within 1 month after the index date $(n=2738)$; those under 18 years of age $(n=4017)$; and those with missing information about age or sex $(n=4)$ in both the CVF and no-CVF cohorts; were excluded. For each CVF patient, a no-CVF participant was frequency-matched by the index year of CVF diagnosis, age (every 5 year span), sex and comorbidities of diabetes (ICD-9-CM code, 250), hypertension (ICD-9-CM codes, 401-405), hyperlipidemia (ICD-9-CM code, 272), atrial fibrillation (ICD-9-CM code, 427.31), chronic kidney disease (CKD; ICD-9-CM codes, 580-589) and chronic obstructive pulmonary disease (COPD; ICD-9-CM codes, 491, 492 and 496) (figure 1). Coexisting comorbidities were identified before the index date, with at least one time of principal or secondary diagnoses documented in hospitalizations during the period 2000 to 2010. We have also added Charlson comorbidity index (CCI) score as a confounding factor. Summary of ICD-9-CM codes applied for disease definition are presented in online supplementary table 1.

\section{Outcome}

The main outcome was hospitalisation with a new diagnosis of $\mathrm{AD}$, CHF, pneumonia, or ARDS during the follow-up period. Both the CVF and no-CVF cohorts were followed up until the diseases appeared or they were censored because of loss to follow-up, death, or the end of December 31, 2010, whichever occurred first.

\section{Statistical analysis}

A chi-square test and Student's t-test were used to evaluate the differences in the distribution of categorical and continuous variables, respectively, between the CVF and no-CVF cohorts. The overall, sex-specific, agespecific and comorbidity-specific incidence densities of $\mathrm{AD}, \mathrm{CHF}$, pneumonia and ARDS were estimated for each cohort. To address the concern of constant proportionality, we examined the proportional hazard model assumption using a test of scaled Schoenfeld residuals. The results showed that there was no significant relationship between Schoenfeld residuals for CVF and follow-up time ( $p$-value $=0.06$ ) in the model evaluating the $\mathrm{AD}$ risk and Schoenfeld residuals for CVF and follow-up time ( $p$-value $=0.18)$ in the model evaluating the ARDS risk. In the model evaluating the CHF and pneumonia risk throughout overall follow-up period, the results of the test revealed a significant relationship between Schoenfeld residuals for CVF and follow-up time, suggesting the proportionality assumption was violated. The relative risks of $\mathrm{AD}, \mathrm{CHF}$, pneumonia and ARDS in the CVF cohort compared with the no-CVF cohort were analysed using univariable and multivariable Cox proportional hazard regression models and presented as HRs and 95\% CIs. The multivariable models were simultaneously adjusted for age, sex and comorbidities of hypertension, diabetes, hyperlipidemia, atrial fibrillation, CKD and COPD. We further tested the interaction between gender and VCF; between age and VCF; and between comorbidity and VCF by including a cross-product term in the model. Further analysis was performed to assess whether the association of CVF with $\mathrm{AD}, \mathrm{CHF}$, pneumonia and ARDS varied according to the levels of CVF. All statistical analyses were performed using SAS 9.4 software (SAS Institute, Cary, North Carolina, USA), and we set the significance level at less than 0.05 for two-sided testing of $\mathrm{P}$ values.

\section{Patient and public involvement}

There was no patient or public involvement in this study.

\section{RESULTS}

\section{Demographics and comorbidity}

In this study, 108,935 CVF patients and 108935 matched no-CVF participants with similar distributions of age, sex and comorbidities were assessed (table 1). In the CVF cohort, $\geq 44.3 \%$ of patients were aged $\geq 65$ years, and $55.3 \%$ of the patients were women (table 1). The mean age of the patients was $58.8 \pm 18.8$ years in the CVF cohort and $58.3 \pm 18.8$ years in the no-CVF cohort. Both cohorts had a medical history of hypertension (26.0\%), diabetes $(15.2 \%)$, COPD (5.3\%), hyperlipidemia (5.2\%), atrial fibrillation $(1.2 \%)$ and CKD $(3.5 \%)$. Patients of CVF cohort were more prevalent with CCI than no-CVF cohort.

\section{Primary outcomes}

Overall, the incidence of $\mathrm{AD}$ was 1.22 -fold higher in the CVF cohort than in the no-CVF cohort (4.85 vs 3.99 per 10000 person-years), with an adjusted HR (aHR) of 1.23 (95\% CI=1.03-1.45) (table 2). The aHR of AD among women was significantly higher in the CVF cohort than in the no-CVF cohort $(\mathrm{aHR}=1.40,95 \% \mathrm{CI}=1.09-1.79)$. The age-specific relative hazard of $\mathrm{AD}$ in the $\mathrm{CVF}$ cohort was higher than that in the no-CVF cohort for age $\leq 49$ group. The relative hazard of $\mathrm{AD}$ was higher in the CVF cohort than in the no-CVF cohort for patients without comorbidities $(\mathrm{aHR}=1.38,95 \% \mathrm{CI}=1.04-1.83)$. In all stratifications, the risk of CHF, pneumonia and ARDS remained higher in the CVF cohort than in the no-CVF cohort.

\section{Subtypes analysis}

Compared with patients without CVF, the risk of $\mathrm{AD}$ was 1.33-fold (95\% CI=1.11-1.60) higher in CVF-lumbar patients and was 1.25-fold (95\% CI=1.05-1.48) higher in CVF patients without SCI (table 3). The risk of CHF and pneumonia remained higher in patients with various levels of CVF than in patients without CVF. table 3 also 
Table 1 Comparison of demographics and comorbidity between clinical vertebral fracture patients and controls

\begin{tabular}{|c|c|c|c|}
\hline & \multicolumn{2}{|c|}{ Clinical vertebral fracture } & \multirow[b]{3}{*}{$P$ value } \\
\hline & $\begin{array}{l}\text { Yes } \\
(n=108935)\end{array}$ & $\begin{array}{l}\text { No } \\
(n=108935)\end{array}$ & \\
\hline & $n(\%)$ & $n(\%)$ & \\
\hline Age, years* & & & 0.99 \\
\hline$\leq 49$ & $36313(33.3)$ & 36310 (33.3) & \\
\hline $50-64$ & $24341(22.3)$ & $24345(22.4)$ & \\
\hline$\geq 65$ & $48281(44.3)$ & $48280(44.3)$ & \\
\hline Mean (SD)† & $58.8(18.8)$ & $58.3(18.8)$ & $<0.001$ \\
\hline Gender* & & & 0.99 \\
\hline Female & $60216(55.3)$ & $60218(55.3)$ & \\
\hline Male & $48719(44.7)$ & $48717(44.7)$ & \\
\hline \multicolumn{4}{|l|}{ Comorbidity* } \\
\hline Hypertension & $28339(26.0)$ & $28338(26.0)$ & 0.99 \\
\hline Diabetes & $16553(15.2)$ & $16554(15.2)$ & 0.99 \\
\hline Hyperlipidemia & $5692(5.2)$ & $5695(5.2)$ & 0.98 \\
\hline Atrial fibrillation & $1381(1.2)$ & $1377(1.2)$ & 0.94 \\
\hline CKD & $3810(3.5)$ & $3814(3.5)$ & 0.96 \\
\hline COPD & $5865(5.3)$ & $5867(5.3)$ & 0.98 \\
\hline $\mathrm{CCl}$ score $^{*}$ & & & $<0.001$ \\
\hline 0 & $77930(71.5)$ & $82878(76.1)$ & \\
\hline 1 & $17489(16.1)$ & $15662(14.4)$ & \\
\hline 2 & $7079(6.5)$ & $5378(4.9)$ & \\
\hline three or more & $6437(5.9)$ & $5017(4.6)$ & \\
\hline
\end{tabular}

${ }^{*}$ Chi-square test examined categorical data.

†T-test examined continuous.

shows that patients with various levels of CVF, except for those with sacrum or coccyx fractures, had a significantly higher risk of ARDS than did patients without CVF.

Figure 2A-2D show that the CVF cohort had a significantly higher cumulative proportion of $\mathrm{AD}(\mathrm{p}=0.02$; figure 2A), CHF $(p<0.001$; figure $2 \mathrm{~B})$, pneumonia $(p<0.001$; figure 2C) and ARDS $(p<0.001$; figure 2D) than did the no-CVF cohort.

\section{DISCUSSION}

To the best of our knowledge, this is the first populationbased, longitudinal cohort study to focus on the correlation between CVF and the subsequent risks of specific cardiopulmonary diseases. The main results demonstrated that CVF is significantly associated with an increased risk of several specific cardiopulmonary diseases, including $\mathrm{AD}, \mathrm{CHF}$, pneumonia and ARDS.

\section{Demographics and comorbidity}

In our study, patients older than 65 years and females accounted for the majority of participants. In fact, the incidence and prevalence of vulnerable fractures, accompanied with population ageing and subsequent frequently occurring home accidents, are steadily rising. ${ }^{38}$
In addition, CVF in women is constantly a consequence of postmenopausal bone loss. ${ }^{58}$ According to recent studies, the prevalence of women older than 50 years who experienced at least one CVF event was 23\%-26\%, which was higher than that of men $(21.5 \%) .{ }^{39}{ }^{40}$ It is noteworthy that young adults aged $\leq 49$, though represented the minority of CVF patients, bore a significant heightened risk of developing adverse outcomes in the following analyses. We speculate that CVF in young adults could have more prominent influence on the outcome diseases without the interaction of multiple potential comorbidities and unknown confounders. Another explanation is that CVF is less frequent in a young, healthy population; it could be more severe and detrimental, strengthening the correlations between the investigated diseases.

\section{Clinical vertebral fracture and aortic dissection}

In our analysis, with or without CVF, the incidence of $\mathrm{AD}$ was higher in men, elderly patients older than 65 years, and those with coexisting comorbidities; this finding is in line with previous epidemiological investigations. ${ }^{11241}$ Moreover, compared with patients without CVF, CVF patients, especially female patients, younger population (age $\leq 49$ ) and those without comorbidities, bore a higher risk of subsequent AD development. Studies that have focused on this correlation are scarce. Interestingly, prior studies have provided evidence for the strong correlation between poor bone health with major fragility fracture and abdominal aortic calcifications. ${ }^{42}{ }^{43}$ With the progressive destruction of intima-media layer accompanied with new bone-like tissue deposition in the aortic wall, aneurysm or dissection might tend to occur. Other potential explanations we suppose include the intractable pain induced by fractures, accompanied with increments in sympathetic tone, stress, hypertension and the impact on the vascular wall, as well as an unfavourable sedentary life style could all contribute to the formation of $\mathrm{AD}$.

\section{Clinical vertebral fracture and congestive heart failure}

Our study indicated one counterintuitive result that women bore a higher overall incidence of CHF than men did. However, previous investigations of sex-specific epidemiology of CHF have demonstrated that women with atrial fibrillation have a higher incidence of heart failure with preserved ejection fraction, especially in very old age compared with men. ${ }^{44-46}$ In this study, CVF was associated with an increased risk of CHF, and the results remained statistically significant across various age and sex strata, as well as with or without comorbidities. In a cross-sectional analysis, Lyons $e t a l^{47}$ demonstrated that more than onetenth of heart failure patients had radiologic recognisable vertebral fracture, and among those, multiple vertebral fractures accounted for one half, indicating the close correlation between these two diseases. Moreover, Sennerby $e t a l^{48}$ conducted a twin population studyand proposed that specific genes involved in cellular mechanisms that shared by the vasculature and bone might connect the close relationship between cardiovascular diseases and fractures. Additionally, 
Table 2 Incidence and adjusted HR of outcome by sex, age and comorbidity for clinical vertebral fracture patients compared with controls

\begin{tabular}{|c|c|c|c|c|c|c|c|c|}
\hline \multirow[b]{3}{*}{ Variables } & \multicolumn{6}{|c|}{ Clinical vertebral fracture } & \multicolumn{2}{|c|}{ Compared with control } \\
\hline & \multicolumn{3}{|l|}{ Yes } & \multicolumn{3}{|l|}{ No } & \multirow[b]{2}{*}{$\begin{array}{l}\text { Crude HR } \\
(95 \% \mathrm{Cl})\end{array}$} & \multirow[b]{2}{*}{$\begin{array}{l}\text { Adjusted HR } \\
(95 \% \mathrm{Cl})\end{array}$} \\
\hline & Events $\mathbf{n}$ & PY & Rate† & Events $\mathbf{n}$ & PY & Rate† & & \\
\hline \multicolumn{9}{|l|}{ Aortic dissection } \\
\hline All & 286 & 589915 & 4.85 & 245 & 614133 & 3.99 & $1.22(1.02 \text { to } 1.44)^{\star}$ & $1.23(1.03 \text { to } 1.45)^{\star}$ \\
\hline \multicolumn{9}{|l|}{ Gender } \\
\hline Female & 149 & 322213 & 4.62 & 109 & 333909 & 3.26 & $1.42(1.11 \text { to } 1.82)^{\star \star}$ & $1.40(1.09 \text { to } 1.79)^{\star \star}$ \\
\hline Male & 137 & 267703 & 5.12 & 136 & 280224 & 4.85 & 1.05 (0.83 to 1.33$)$ & 1.08 (0.85 to 1.37$)$ \\
\hline$P$ for interaction & & & & & & & & 0.09 \\
\hline \multicolumn{9}{|l|}{ Age, years } \\
\hline$\leq 49$ & 19 & 230604 & 0.82 & 8 & 229738 & 0.35 & $2.37(1.04 \text { to } 5.40)^{\star}$ & $2.37(1.03 \text { to } 5.41)^{\star}$ \\
\hline $50-64$ & 43 & 139107 & 3.09 & 30 & 143099 & 2.10 & 1.48 (0.93 to 2.36$)$ & 1.45 (0.91 to 2.31$)$ \\
\hline$\geq 65$ & 224 & 220204 & 10.2 & 207 & 241296 & 8.58 & 1.19 (0.99 to 1.44$)$ & 1.17 (0.97 to 1.42$)$ \\
\hline $\mathrm{P}$ for interaction & & & & & & & & 0.29 \\
\hline \multicolumn{9}{|l|}{ Comorbidity§ } \\
\hline No & 117 & 411117 & 2.85 & 86 & 421520 & 2.04 & $1.40(1.06 \text { to } 1.85)^{\star}$ & $1.38(1.04 \text { to } 1.83)^{\star}$ \\
\hline Yes & 169 & 178798 & 9.45 & 159 & 192612 & 8.25 & 1.15 (0.92 to 1.42$)$ & 1.14 (0.91 to 1.41$)$ \\
\hline$P$ for interaction & & & & & & & & 0.28 \\
\hline \multicolumn{9}{|l|}{$\begin{array}{l}\text { Congestive heart } \\
\text { failure }\end{array}$} \\
\hline All & 6866 & 576513 & 119.1 & 5411 & 603639 & 89.6 & $1.33(1.28 \text { to } 1.38)^{\star \star \star}$ & $1.35(1.30 \text { to } 1.40)^{\star \star \star}$ \\
\hline \multicolumn{9}{|l|}{ Gender } \\
\hline Female & 4689 & 312775 & 149.9 & 3649 & 326705 & 111.7 & $1.34(1.29 \text { to } 1.40)^{\star \star \star}$ & $1.33(1.27 \text { to } 1.39)^{\star \star \star}$ \\
\hline Male & 2177 & 263738 & 82.5 & 1762 & 276934 & 63.6 & $1.30(1.22 \text { to } 1.38)^{\star \star \star}$ & $1.38(1.30 \text { to } 1.47)^{\star \star \star}$ \\
\hline P for interaction & & & & & & & & 0.38 \\
\hline \multicolumn{9}{|l|}{ Age, years } \\
\hline$\leq 49$ & 233 & 230058 & 10.1 & 142 & 229391 & 6.19 & $1.63(1.33 \text { to } 2.01)^{\star \star \star}$ & $1.64(1.33 \text { to } 2.03)^{\star \star \star}$ \\
\hline $50-64$ & 733 & 137433 & 53.3 & 577 & 141714 & 40.7 & $1.31(1.18 \text { to } 1.47)^{\star \star \star}$ & $1.31(1.17 \text { to } 1.46)^{\star \star \star}$ \\
\hline$\geq 65$ & 5900 & 209022 & 282.3 & 4692 & 232533 & 201.8 & $1.41(1.35 \text { to } 1.46)^{\star \star \star}$ & $1.38(1.33 \text { to } 1.44)^{\star * *}$ \\
\hline$P$ for interaction & & & & & & & & 0.51 \\
\hline \multicolumn{9}{|l|}{ Comorbidity§ } \\
\hline No & 2115 & 406910 & 52.0 & 1508 & 418712 & 36.0 & $1.45(1.35 \text { to } 1.54)^{\star \star \star}$ & $1.42(1.33 \text { to } 1.52)^{\star \star \star}$ \\
\hline Yes & 4751 & 169603 & 280.1 & 3903 & 184927 & 211.1 & $1.33(1.28 \text { to } 1.39)^{\star \star \star}$ & $1.31(1.26 \text { to } 1.37)^{\star \star * *}$ \\
\hline$P$ for interaction & & & & & & & & 0.04 \\
\hline \multicolumn{9}{|l|}{ Follow-up period } \\
\hline$<5$ years & 5193 & 194850 & 266.5 & 3753 & 197188 & 190.3 & $1.40(1.34 \text { to } 1.46)^{\star \star \star}$ & $1.07(1.00 \text { to } 1.15)^{\star}$ \\
\hline$\geqq 5$ years & 1673 & 166386 & 100.6 & 1658 & 177139 & 93.6 & $1.34(1.29 \text { to } 1.40)^{\star \star \star}$ & $1.17(1.09 \text { to } 1.25)^{\star \star \star}$ \\
\hline \multicolumn{9}{|l|}{ Pneumonia } \\
\hline All & 15912 & 561694 & 283.3 & 10929 & 595609 & 183.5 & $1.54(1.51 \text { to } 1.58)^{\star \star \star}$ & $1.57(1.54 \text { to } 1.61)^{\star \star \star}$ \\
\hline \multicolumn{9}{|l|}{ Gender } \\
\hline Female & 8740 & 306705 & 285.0 & 6126 & 323229 & 189.5 & $1.50(1.46 \text { to } 1.55)^{\star \star \star}$ & $1.49(1.44 \text { to } 1.53)^{\star \star \star}$ \\
\hline Male & 7172 & 254989 & 281.3 & 4803 & 272380 & 176.3 & $1.59(1.53 \text { to } 1.65)^{\star \star \star}$ & $1.68(1.62 \text { to } 1.75)^{\star \star \star}$ \\
\hline$P$ for interaction & & & & & & & & 0.02 \\
\hline \multicolumn{9}{|l|}{ Age, years } \\
\hline$\leq 49$ & 1468 & 226184 & 64.9 & 557 & 228317 & 24.4 & $2.66(2.41 \text { to } 2.93)^{\star \star \star}$ & $2.56(2.32 \text { to } 2.82)^{\star \star \star *}$ \\
\hline $50-64$ & 2018 & 134598 & 149.9 & 1330 & 140288 & 94.8 & $1.59(1.48 \text { to } 1.70)^{\star \star \star}$ & $1.57(1.47 \text { to } 1.69)^{\star \star \star}$ \\
\hline
\end{tabular}


Table 2 Continued

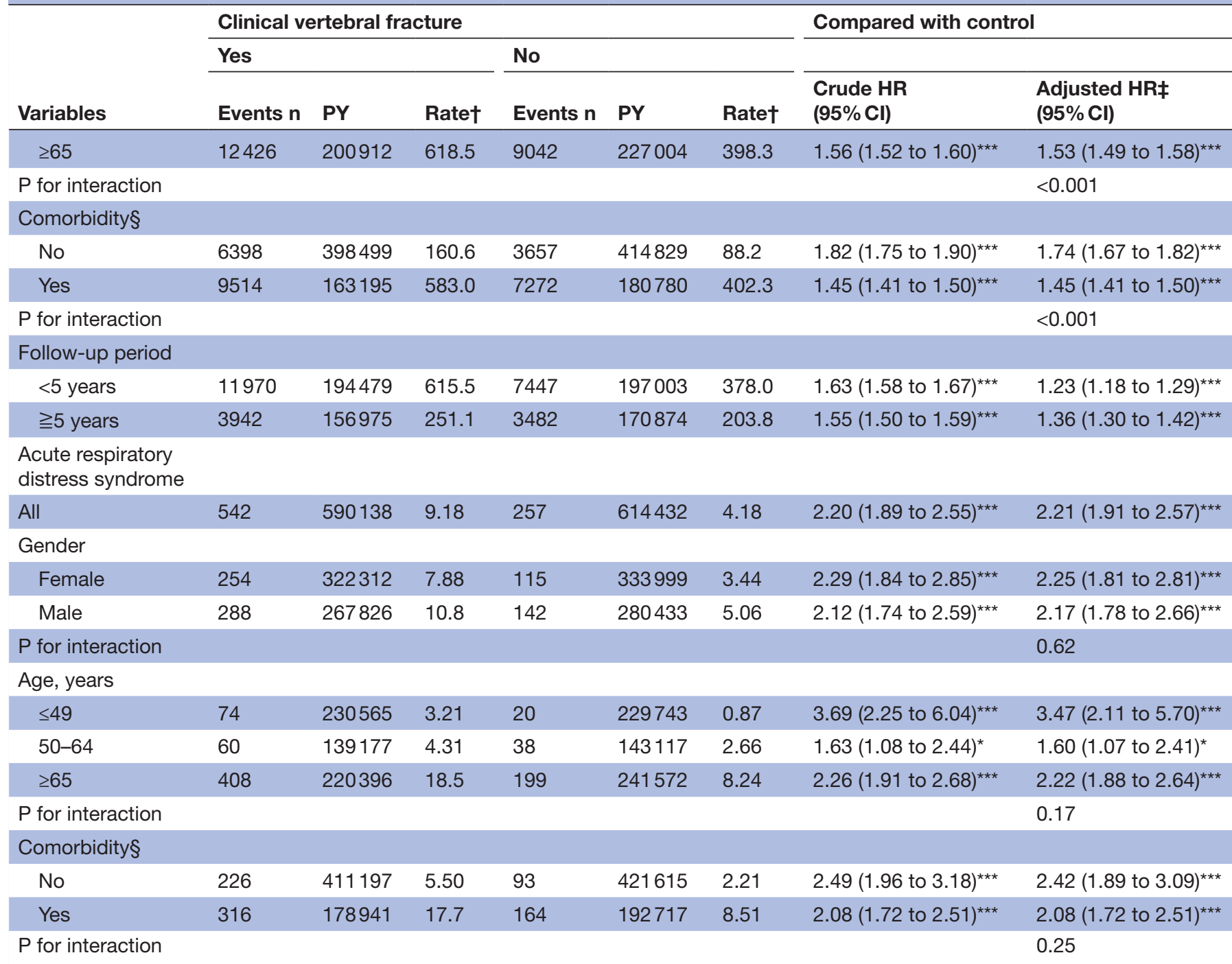

$\mathrm{p}<0.05,{ }^{* *} \mathrm{p}<0.01,{ }^{* * *} \mathrm{p}<0.001$.

† Rate, incidence rate, per 10,000 person-years; Crude HR: relative hazard ratio.

$\ddagger$ Adjusted HR: adjusted hazard ratio controlling for age, sex, comorbidities of hypertension, diabetes, hyperlipidemia, atrial fibrillation,

CKD, COPD and CCI score.

§Comorbidity: Patients with any one of the comorbidities hypertension, diabetes, hyperlipidemia, atrial fibrillation, CKD and COPD were classified as the comorbidity group.

PY, person-years.

the most common aetiology of CVF, osteoporosis, together with CHF, share common risk factors and etiologic mechanisms, including advantaged age, female sex, hypovitaminosis D, renal insufficiency, diabetes, a smoking habit, activation of the renin-angiotensin-aldosterone system, hypersecretion of parathyroid hormones and oxidative/ nitrosative stress. ${ }^{23}{ }^{474-52}$ In a meta-analysis, Veronese $e t a p^{33}$ concluded that alterations in signalling pathways of bone remodelling and arterial calcifications could contributed to the higher cardiovascular risk. Indeed, diffuse vascular calcifications accompanied with bone loss could result in a higher afterload on the left ventricle, leading to subsequent left ventricular hypertrophy and finally, congestive heart failure. ${ }^{42}{ }^{43}$ Furthermore, unfavourable outcomes following fracture, including a loss of functional and social activities, dependency with poor quality of life, higher serum cortisol levels accompanied with depressive disorder, higher inflammatory markers, lower drug and diet compliance, a sedentary life style and arrhythmia or cardiac ischaemic events caused by high sympathetic activity, might all contribute to the deterioration of heart function. 5054

Clinical vertebral fracture and pneumonia, acute respiratory distress syndrome and subtypes analysis

Our study results reveal that patients with CVF bore a significantly heightened risk of subsequent pneumonia and ARDS across all strata of age and sex and irrespective of the presence of comorbidities. Further analyses 
Table 3 Comparisons of incidence, and HR of outcome by subtypes of clinical vertebral fracture

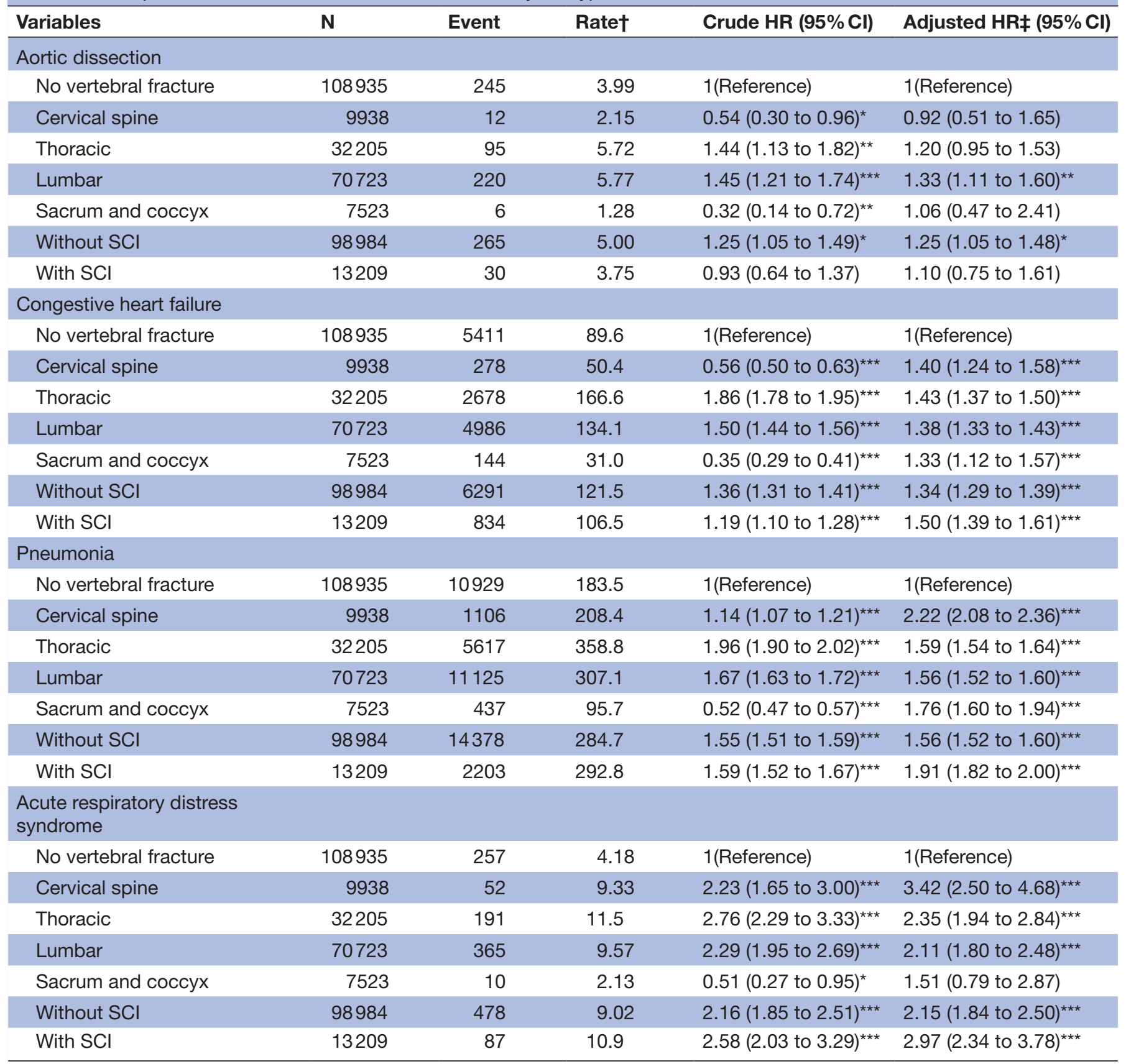

$\mathrm{p}<0.05,{ }^{* *} \mathrm{p}<0.01,{ }^{* \star *} \mathrm{p}<0.001$.

†Rate, incidence rate, per 10,000 person-years; Crude HR: relative hazard ratio.

$\ddagger$ Adjusted HR: adjusted hazard ratio controlling for age, sex, comorbidities of hypertension, diabetes, hyperlipidemia, atrial fibrillation, CKD, COPD and CCI scorelCD-9-CM: Cervical spine: 805.0-805.18, 806.0-806.19; Thoracic: 805.2, 805.3, 806.2-806.39; Lumbar: 805.4, 805.5, 806.4, 806.5; Sacrum and coccyx: 805.6, 805.7, 806.6-806.79; SCI involved or Not: Without SCI: 805-805.9 \& With SCI: 806-806.9.

demonstrated the strongest correlation between cervical CVF combined with SCI and risks of pneumonia and ARDS. In a 2year retrospective multicenter trauma registry analysis, Fletcher et $a \tilde{l}^{55}$ noted that $16 \%$ of elderly patients older than 65 years with cervical spine trauma ultimately developed pneumonia. Other studies have revealed the incidence of pulmonary complications following cervical spine trauma to be $35 \%-95 \%,{ }^{56} 57$ and among these complications, the most common type was pneumonia and atelectasis, although ARDS was the most severe type. ${ }^{58-60}$ There are several possible explanations. First, deformity of the vertebral body or even kyphosis might decrease the lung capacity and therefore impair the pulmonary function. Prior studies have indicated that a single vertebral fracture would decrease the predicted forced vital capacity by $9 \%$, increase the risk of restrictive lung disease. ${ }^{1261}$ Harrison et a $b^{62}$ conducted a systemic review of 4 case-control studies and reported that women 
(A)

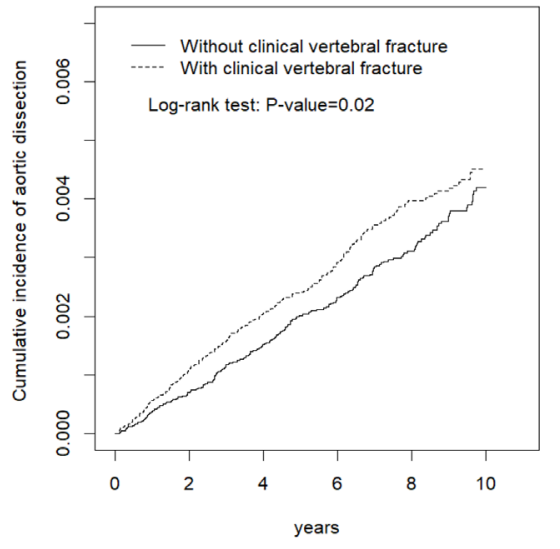

(C)

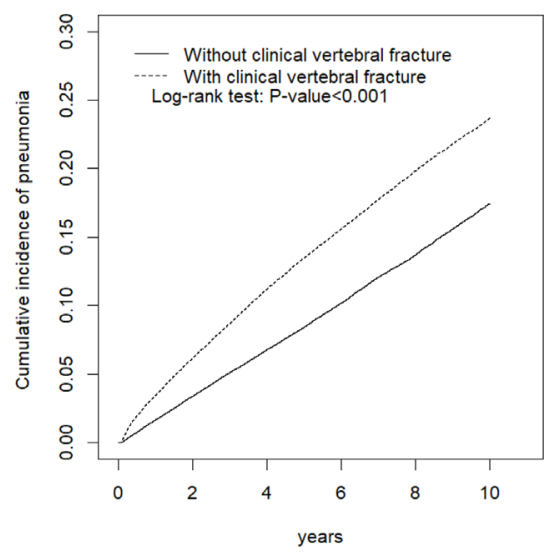

(B)

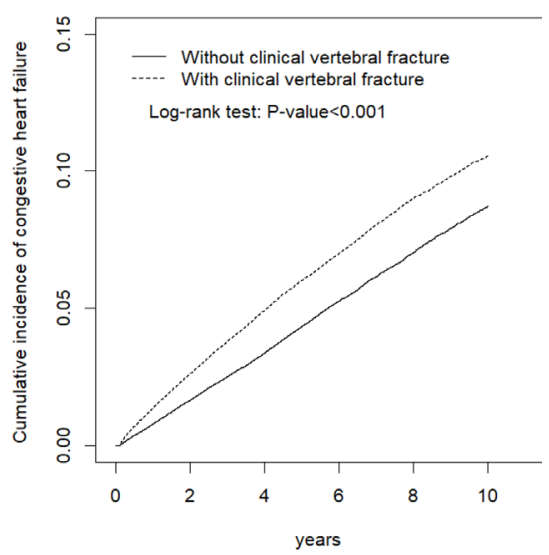

(D)

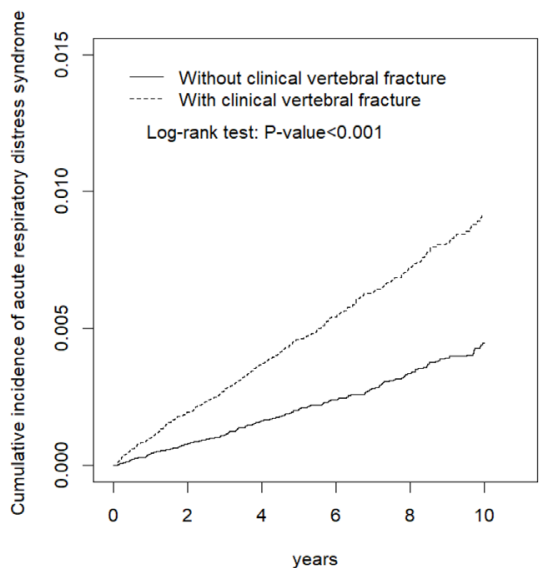

Figure 2 Cummulative incidence of aortic dissection (A), congestive heart failure (B), pneumonia (C) and acute respiratory distress syndrome $(D)$ in patients with clinical vertebral fracture and comparison patients

with osteoporotic vertebral fractures or kyphosis were associated with decreased predicted vital capacity, as well as total lung capacity. Furthermore, Krege et $a l^{63}$ estimated that spine fracture burden is linked with restrictive, but not obstructive lung disease. The authors further concluded that patients with marginally compensated pulmonary function may not tolerate the superimposed lung restrictive change resulting from vertebral fractures and thus, leading to a further compromised pulmonary function and subsequent lung diseases. Second, cervical CVF combined with SCI might cause paralysis of the diaphragm and hypoactivity of the respiratory accessory muscles, which results in hypoventilation. In addition, the imbalance of sympathetic-parasympathetic interactions would result in an elevated airway tone, bronchorrhea and poor clearance, which are all associated with the development of various pulmonary complications. ${ }^{6465}$ Third, patients with SCI are prone to develop aspiration and subsequent pulmonary infection due to impaired neuromuscular transmission. Finally, similar to rib fractures, worsening pain related to CVF might impair cough and secretion clearance, leading to atelectasis and subsequent lung infection. ${ }^{24}$

\section{Limitations}

The major strength of our study is sampling from a large nationwide database, which covers nearly $100 \%$ of all residents in Taiwan, and stable outcomes could be achieved with such adequate, representative samples. However, the inevitable limitations should be discussed. First, all disease definitions and sample selection in our study were based on the ICD-9-CM coding, which has been rigorously scrutinised and peer-reviewed by clinical physicians, the declaration unit of medical institutions and finally the NHI administration. However, miscoding or misclassification might still exist, although it is considered rare. Similarly, diagnostic criteria applied, as well as physician's ability to diagnose the investigated diseases might vary among different hospitals and areas. Second, retrospective dataset analysis results cannot be used to determine causal relationships. Third, several crucial variables could not be obtained from our dataset, including family history, education and socioeconomic status, information of life style and physical activity, body weight, smoking habits, disease severity, laboratory results, radiologic reports and estimated pain scores, which are potential confounders that might have affected the results. Fourth, a considerable portion of vertebral fracture patients with slight or no symptoms might not have been diagnosed or might have even been overlooked in clinical settings; thus, the true incidence of CVF and the inferred association between CVF and cardiopulmonary diseases could be underestimated. Fifth, patients with CVF might have one or more overlapping etiologies include osteoporosis, trauma and malignancies, etc. Therefore, it was technically infeasible 
to simply divide the CVF patients into several subgroups for sub-analysis based on the coding of etiologies. Sixth, our sampled participants were retrieved from NHIRD from January 1, 2000, to December 31, 2010. Ageing property of the data might not truly reflect the current medical conditions. Finally, because of geographic and epidemiologic discrepancies, our results might not be applicable to other countries or regions.

\section{CONCLUSION}

In conclusion, our study results support the hypothesis that CVF is associated with subsequent risks of $\mathrm{AD}$, CHF, pneumonia and ARDS. Future studies are warranted to delineate the actual pathophysiologic mechanisms underlying this correlation and to develop optimal strategies for reducing the heath care burden of CVF and its complications. Based on our results, we suggest that patients with CVF should be targeted for further screening and preventive interventions for cardiopulmonary diseases.

\section{Author affiliations}

${ }^{1}$ Department of Emergency Medicine, Taichung Tzu Chi Hospital, Taichung City,

Taiwan

${ }^{2}$ Department of Emergency Medicine, School of Medicine, Tzu Chi University, Hualien, Taiwan

${ }^{3}$ Department of Emergency Medicine, Trauma and Emergency Center, China Medical University Hospital, Taichung City, Taiwan

${ }^{4}$ Management Office for Health Data, China Medical University Hospital, Taichung City, Taiwan

${ }^{5}$ College of Medicine, China Medical University, Taichung City, Taiwan

${ }^{6}$ Graduate Institute of Biomedical Sciences and School of Medicine, College of Medicine, China Medical University, Taichung City, Taiwan

${ }^{7}$ Center of Augmented Intelligence in Healthcare, Department of Nuclear Medicine and PET Center, China Medical University Hospital, Taichung City, Taiwan

${ }^{8}$ Department of Medical Research \& Molecular and Genomic Epidemiology Center, China Medical University Hospital, Taichung City, Taiwan

${ }^{9}$ Center for General Education \& Master Program of Digital Health Innovation, China Medical University, Taichung City, Taiwan

Contributors The authors' individual contributions are outlined as follows. Conception and design: F-YL. and T-YY. Administrative support: T-YY. Data collection and organization: F-YL, W-KC, C-CL, C-HK, T-YY \& C-YL. Data analysis and interpretation: F-YL, W-KC, C-CL, C-HK, T-YY \& C-YL. Manuscript writing: F-YL, WKC, C-CL, C-HK, T-YY \& C-YL. Final approval of the manuscript: F-YL, W-KC, C-CL, $C-H K, T-Y Y \& C-Y L$.

Funding This work was supported by grants from the Taiwan Ministry of Health and Welfare Clinical Trial Center (MOHW108-TDU-B-212-133004); China Medical University Hospital (DMR-107-125); Academia Sinica Stroke Biosignature Project (BM10701010021); MOST Clinical Trial Consortium for Stroke (MOST 108-2321B-039-003-); Tseng-Lien Lin Foundation, Taichung, Taiwan; Katsuzo and Kiyo Aoshima Memorial Funds, Japan; The Department of Medical Research at Mackay Memorial Hospital (MMH105-87; MMH-106-81; MMH-107-71; MMH-107-102; MMH-107-135).

Competing interests None declared.

Patient consent for publication Not required.

Ethics approval This study was approved by the Ethics Review Board of China Medical University Hospital, Taiwan (CMUH-104-REC2-115-CR4). The IRB waived the consent requirement.

Provenance and peer review Not commissioned; externally peer reviewed.

Data availability statement Data may be obtained from a third party and are not publicly available.
Open access This is an open access article distributed in accordance with the Creative Commons Attribution Non Commercial (CC BY-NC 4.0) license, which permits others to distribute, remix, adapt, build upon this work non-commercially, and license their derivative works on different terms, provided the original work is properly cited, appropriate credit is given, any changes made indicated, and the use is non-commercial. See: http://creativecommons.org/licenses/by-nc/4.0/.

\section{ORCID iDs}

Chia-Hung Kao http://orcid.org/0000-0002-6368-3676

Tse-Yen Yang http://orcid.org/0000-0002-3165-132X

\section{REFERENCES}

1 Longo UG, Loppini M, Denaro L, et al. Conservative management of patients with an osteoporotic vertebral fracture: a review of the literature. J Bone Joint Surg Br 2012;94:152-7.

2 Longo UG, Loppini M, Denaro L, et al. Osteoporotic vertebral fractures: current concepts of conservative care. Br Med Bull 2012;102:171-89.

$3 \mathrm{CW}$ Y, Hsieh MK, Chen LH, et al. Percutaneous balloon kyphoplasty for the treatment of vertebral compression fractures. BMC Surg $2014 ; 14$.

4 Guo J-B, Zhu Y, Chen B-L, et al. Surgical versus non-surgical treatment for vertebral compression fracture with osteopenia: a systematic review and meta-analysis. PLoS One 2015;10:e0127145.

5 Bliuc D, Center JR. Determinants of mortality risk following osteoporotic fractures. Curr Opin Rheumatol 2016;28:413-9.

6 Chih YP, WT W, Lin CL, et al. Vertebral compression fracture related to pancreatic cancer with osteoblastic metastasis: a case report and literature review. Medicine 2016;95:e2670.

7 Lewiecki EM, Laster AJ. Clinical applications of vertebral fracture assessment by dual-energy X-ray absorptiometry. J Clin Endocrinol Metab 2006;91:4215-22.

8 Lindsay Ret al. Risk of new vertebral fracture in the year following a fracture. JAMA 2001;285:320-3.

9 Park SB, Kim J, Jeong JH, et al. Prevalence and incidence of osteoporosis and osteoporotic vertebral fracture in Korea: nationwide epidemiological study focusing on differences in socioeconomic status. Spine 2016;41:328-36.

10 Tolenaar JL, van Bogerijen GHW, Eagle KA, et al. Update in the management of aortic dissection. Curr Treat Options Cardiovasc Med 2013;15:200-13.

11 Melvinsdottir IH, Lund SH, Agnarsson BA, et al. The incidence and mortality of acute thoracic aortic dissection: results from a whole nation study. Eur J Cardiothorac Surg 2016;50::ezw235.:1111-7.

12 Pacini D, Di Marco L, Fortuna D, et al. Acute aortic dissection: epidemiology and outcomes. Int J Cardiol 2013;167:2806-12.

13 Bui AL, Horwich TB, Fonarow GC. Epidemiology and risk profile of heart failure. Nat Rev Cardiol 2011;8:30-41.

14 Givertz MM, Teerlink JR, Albert NM, et al. Acute decompensated heart failure: update on new and emerging evidence and directions for future research. J Card Fail 2013;19:371-89.

15 Maze R, Haddad H. An update in the management of acute decompensated heart failure. Curr Opin Cardiol 2014;29:180-4.

16 Bender MT, Niederman MS. Improving outcomes in communityacquired pneumonia. Curr Opin Pulm Med 2016;22:235-42.

17 Marrie TJ, File TM. Bacterial pneumonia in older adults. Clin Geriatr Med 2016;32:459-77.

18 Kim W-Y, Hong S-B. Sepsis and acute respiratory distress syndrome: recent update. Tuberc Respir Dis 2016;79:53-7.

19 Koh Y. Update in acute respiratory distress syndrome. $j$ intensive care $2014 ; 2$.

20 Chen Y-C, Wu J-C, Liu L, et al. Hospitalized osteoporotic vertebral fracture increases the risk of stroke: a population-based cohort study. J Bone Miner Res 2013;28:516-23.

21 Laroche M, Pecourneau V, Blain H, et al. Osteoporosis and ischemic cardiovascular disease. Joint Bone Spine 2016.

22 Silverman SL, Delmas PD, Kulkarni PM, et al. Comparison of fracture, cardiovascular event, and breast cancer rates at 3 years in postmenopausal women with osteoporosis. J Am Geriatr Soc 2004;52:1543-8.

23 Ni Mhuircheartaigh O, Crowson CS, Gabriel SE, et al. Fragility fractures are associated with an increased risk for cardiovascular events in women and men with rheumatoid arthritis: a populationbased study. J Rheumatol 2017;44:558-64.

$24 \mathrm{Kim} \mathrm{B}$, Kim J, Jo YH, et al. Risk of pneumonia after vertebral compression fracture in women with low bone density: a populationbased study. Spine 2018;43:E830-5. 
25 Melton LJ, Kallmes DF. Epidemiology of vertebral fractures: implications for vertebral augmentation. Acad Radiol 2006;13:538-45.

26 Shou-Hsia C, Tung-Liang C. The effect of universal health insurance on health care utilization in Taiwan: results from a natural experiment. JAMA : the journal of the American Medical Association 1997;278:89-93.

27 Peng Y-C, Lin C-L, Yeh H-Z, et al. Diverticular disease and additiona comorbidities associated with increased risk of dementia. $J$ Gastroenterol Hepatol 2016;31:1816-22.

28 Chen Y-T, Su J-S, Tseng C-W, et al. Inflammatory bowel disease on the risk of acute pancreatitis: a population-based cohort study. $J$ Gastroenterol Hepatol 2016;31:782-7.

29 Lee C-H, Hsu W-C, Ko J-Y, et al. Trends in the management of peritonsillar abscess in children: a nationwide population-based study in Taiwan. Int J Pediatr Otorhinolaryngol 2019;125:32-7.

30 JA S, Chang CC, Wang HM, et al. Antidepressant treatment and mortality risk in patients with dementia and depression: a nationwide population cohort study in Taiwan. Ther Adv Chronic Dis 2019;10.

31 Hong WJ, Chen W, Yeo KJ, et al. Increased risk of osteoporotic vertebral fracture in rheumatoid arthritis patients with new-onset cardiovascular diseases: a retrospective nationwide cohort study in Taiwan. Osteoporos Int 2019.

32 Huang KL, Yeh CC, SI W, et al. Risk of dementia among individuals with psoriasis: a nationwide population-based cohort study in Taiwan. J Clin Psychiatry 2019;80.

33 Lin C-E, Chung C-H, Chen L-F, et al. Risk of incident hypertension, diabetes, and dyslipidemia after first posttraumatic stress disorder diagnosis: a nationwide cohort study in Taiwan. Gen Hosp Psychiatry 2019;58:59-66.

34 Cheng $\mathrm{C}-\mathrm{L}$, Chien $\mathrm{H}-\mathrm{C}$, Lee $\mathrm{C}-\mathrm{H}$, et al. Validity of in-hospital mortality data among patients with acute myocardial infarction or stroke in national health insurance research database in Taiwan. Int $J$ Cardiol 2015;201:96-101.

35 Cheng C-L, Kao Y-HY, Lin S-J, et al. Validation of the National health insurance research database with ischemic stroke cases in Taiwan. Pharmacoepidemiol Drug Saf 2011;20:236-42.

36 Cheng C-L, Lee C-H, Chen P-S, et al. Validation of acute myocardial infarction cases in the National health insurance research database in Taiwan. J Epidemiol 2014;24:500-7.

37 TW H, Ruan SY, Huang CT, et al. Validity of ICD9-CM codes to diagnose chronic obstructive pulmonary disease from national health insurance claim data in Taiwan. Int J Chron Obstruct Pulmon Dis 2018;13:3055-63.

38 Bouyer B, Vassal M, Zairi F, et al. Surgery in vertebral fracture: epidemiology and functional and radiological results in a prospective series of 518 patients at 1year's follow-up. Orthopaedics \& Traumatology: Surgery \& Research 2015;101:11-15.

39 Jackson SA, Tenenhouse A, Robertson L. Vertebral fracture definition from population-based data: preliminary results from the Canadian multicenter osteoporosis study (CaMos). Osteoporosis International 2000;11:680-7.

40 Kendler DL, Bauer DC, Davison KS, et al. Vertebral fractures: clinica importance and management. Am J Med 2016;129:221.e1-221.e10.

41 Yeh T-Y, Chen C-Y, Huang J-W, et al. Epidemiology and medication utilization pattern of aortic dissection in Taiwan. Medicine 2015;94:e1522.

42 Szulc P. Abdominal aortic calcification: a reappraisal of epidemiological and pathophysiological data. Bone 2016;84:25-37.10.1016/j.bone.2015.12.004

43 Thompson B, Towler DA. Arterial calcification and bone physiology: role of the bone-vascular axis. Nat Rev Endocrinol 2012;8:529-43.
44 Hassanein M, Abdelhamid M, Ibrahim B, et al. Gender differences in Egyptian patients hospitalized with heart failure: insights from the European Society of cardiology heart failure long-term registry. ESC Heart Failure 2018;5:1159-64.

45 Madan N, Itchhaporia D, Albert CM, et al. Atrial fibrillation and heart failure in women. Heart Fail Clin 2019;15:55-64.

46 Magnussen C, Niiranen TJ, Ojeda FM, et al. Sex-Specific epidemiology of heart failure risk and mortality in Europe: results from the BiomarCaRE Consortium. JACC Heart Fail 2019;7:204-13.

47 Lyons KJ, Majumdar SR, Ezekowitz JA. The unrecognized burden of osteoporosis-related vertebral fractures in patients with heart failure. Circulation 2011;4:419-24.10.1161/ CIRCHEARTFAILURE.111.961185

48 Sennerby Uet al. Cardiovascular diseases and risk of hip fracture. JAMA 2009;302:1666-73.

49 Aluoch $\mathrm{AO}$, Jessee $\mathrm{R}$, Habal $\mathrm{H}$, et al. Heart failure as a risk factor for osteoporosis and fractures. Curr Osteoporos Rep 2012;10:258-69.

50 Larina VN, Bart BI, Raspopova TN. [Chronic heart failure and osteoporosis]. Kardiologiia 2013;53:76-84.

51 Farhat GN, Cauley JA. The link between osteoporosis and cardiovascular disease. Clin Cases Miner Bone Metab 2008;5:19-34.

52 Gerber Y, Melton LJ, Weston SA, et al. Osteoporotic fractures and heart failure in the community. Am J Med 2011;124:418-25.

53 Veronese N, Stubbs B, Crepaldi G, et al. Relationship between low bone mineral density and fractures with incident cardiovascular disease: a systematic review and meta-analysis. J Bone Miner Res 2017;32:1126-35.

54 Adelborg K, Schmidt M, Sundboll J, et al. Mortality risk among heart failure patients with depression: a nationwide population-based cohort study. J Am Coll Cardiol 2016;67:1318-18.

55 Fletcher DJ, Taddonio RF, Byrne DW, et al. Incidence of acute care complications in vertebral column fracture patients with and without spinal cord injury. Spine 1995;20:1136-46.

56 Jackson AB, Groomes TE. Incidence of respiratory complications following spinal cord injury. Arch Phys Med Rehabil 1994;75:270-5

57 Winslow C, Bode RK, Felton D, et al. Impact of respiratory complications on length of stay and hospital costs in acute cervical spine injury. Chest 2002;121:1548-54.

58 Cotton BA, Pryor JP, Chinwalla I, et al. Respiratory complications and mortality risk associated with thoracic spine injury. J Trauma 2005;59:1400-9

59 Veeravagu A, Jiang B, Rincon F, et al. Acute respiratory distress syndrome and acute lung injury in patients with vertebral column fracture(s) and spinal cord injury: a nationwide inpatient sample study. Spinal Cord 2013;51:461-5.

60 Lieberman IH, Webb JK. Cervical spine injuries in the elderly. J Bone Joint Surg Br 1994;76-B:877-81.

61 Kado DM, Browner WS, Palermo L, et al. Vertebral fractures and mortality in older women: a prospective study. Archives of internal medicine 1999:159:1215-20.

62 Harrison RA, Siminoski K, Vethanayagam D, et al. Osteoporosisrelated kyphosis and impairments in pulmonary function: a systematic review. J Bone Miner Res 2007;22:447-57.

$63 \mathrm{Krege} \mathrm{JH}$, Kendler D, Krohn K, et al. Relationship between vertebral fracture burden, height loss, and pulmonary function in postmenopausal women with osteoporosis. J Clin Densitom 2015;18:506-11

64 Chen Yet al. Identification of risk factors for respiratory complications in upper cervical spinal injured patients with neurological impairment. Acta Orthop Traumatol Turc 2013;47:111-7.

65 Krassioukov A. Autonomic function following cervical spinal cord injury. Respir Physiol Neurobiol 2009;169:157-64. 